\title{
Taste cues control ethanol-induced conditioned taste avoidance but not conditioned tolerance
}

\author{
CHRISTOPHER L. CUNNINGHAM and CHERYL L. HALLETT \\ Oregon Health Sciences University, Portland, Oregon
}

\begin{abstract}
This experiment tested the ability of taste cues to serve as the conditioned stimulus (CS) for conditioned tolerance to ethanol hypothermia. Rats were exposed to a differential Pavlovian conditioning procedure in which the manual oral infusion of one flavor solution was consistently followed by injection of ethanol $(2.25 \mathrm{~g} / \mathrm{kg})$, whereas exposure to another flavor was followed by injection of saline (16 trials each). Control rats received saline after both flavors. Body temperature was recorded continuously using radio telemetry. Ethanol-treated rats developed tolerance to ethanol's hypothermic effect and aversion for the ethanol-paired flavor. However, flavor had no effect on the expression of tolerance, indicating that taste was not an effective CS for conditioned tolerance. This outcome may represent an instance of selective association in which taste cues more readily gain control over ethanol's effect on ingestive behavior, whereas environmental cues more readily gain control over ethanol's thermal effect. These results may also bear on the hypothesized role that ethanol's thermal effect plays in ethanol self-administration and ethanolinduced conditioned taste aversion.
\end{abstract}

Considerable evidence now indicates that many changes in drug effects produced by repeated drug exposure can be attributed to Pavlovian conditioning (Cunningham, Crabbe, \& Rigter, 1984; Sherman, Jorenby, \& Baker, 1988; Siegel, 1985, 1989; Siegel, Krank, \& Hinson, 1987; Stewart \& Eikelboom, 1987). Special attention has been focused on the effect of such conditioning on drug tolerance because of the presumed role that tolerance plays in promoting drug self-administration and dependence (Goudie \& Demellweek, 1986; Hinson \& Siegel, 1980). In the case of ethanol, the literature has been remarkably consistent in showing that Pavlovian conditioning can be importantly involved in the expression of tolerance to ethanol's hypothermic effect. Several studies have shown that tolerance is greater in the presence of stimuli that have been paired with ethanol than in the absence of such stimuli. These studies have also shown that conditioned tolerance to ethanol hypothermia is mediated, at least in part, by a conditioned compensatory hyperthermia (Crowell, Hinson, \& Siegel, 1981; Greeley, Le, Poulos, \& Cappell, 1984; Le, Poulos, \& Cappell, 1979; Mansfield \& Cunningham, 1980; Melchior \& Tabakoff, 1981).

Consideration of the stimuli normally present during oral self-administration of ethanol suggests that taste cues ought to be especially good conditioned stimuli (CSs) for conditioned tolerance based on their temporal proximity

This research was supported in part by NIAAA Grants AA07702 and AA07468. Thanks are extended to Douglas Niehus for his assistance in running this experiment. Portions of these data were presented at the annual meeting of the Research Society on Alcoholism in June 1988 (Charleston, SC). Correspondence should be addressed to Christopher L. Cunningham, Department of Medical Psychology, Oregon Health Sciences University, Portland, OR 97201. and positive correlation with ethanol's effects. Indeed, the taste of ethanol has been offered as the prototypical CS in descriptions of the compensatory response model of conditioned tolerance (Baker, Morse, \& Sherman, 1986, p. 263). It has also been suggested that the purported ability of alcohol's taste to elicit "craving" in alcoholics (e.g., Hodgson \& Rankin, 1976) is due to an association between flavor cues and the unconditioned effects of ethanol (Hinson \& Siegel, 1980). However, although many studies show that taste stimuli can serve as reliable cues for ethanol's aversive effects (cf. Sherman et al., 1988), there are few data to support their alleged role in the mediation of conditioned tolerance.

Only one study appears to have examined specifically the ability of taste cues to serve as the CS for conditioned tolerance to ethanol hypothermia (Sinclair, 1984). In that study, drinking of saccharin or an ethanol-saccharin solution by fluid-deprived rats was followed $60 \mathrm{~min}$ later by injection of ethanol $(2.5 \mathrm{~g} / \mathrm{kg})$. Rats developed a strong aversion to the flavor solutions and avoided the solutions almost completely after two pairings. Measurement of rectal temperature $60 \mathrm{~min}$ after the 12 th flavor-ethanol pairing showed tolerance to ethanol hypothermia. However, there was no difference between the paired flavor-ethanol groups and an unpaired control group that had received 11 previous ethanol injections separated from the flavor solution by $24 \mathrm{~h}$. Moreover, there was no loss of tolerance when the flavor solutions were replaced by water in a subsequent test. Sinclair concluded that tolerance had not been conditioned to stimuli provided by the flavor solutions.

Before dismissing a possible role for taste cues in the control of conditioned tolerance, several aspects of Sinclair's (1984) procedure must be carefully considered. First, because the rats controlled their degree of exposure 
to the flavor CS and because variation in flavor intake was not correlated with drug dose (i.e., dose remained constant), the flavor CS-drug unconditioned stimulus (US) relationship varied over trials. In particular, the duration/ intensity of the flavor CS was greater on early trials than on later trials. One might argue that as the rat reduced its flavor intake over trials, nongustatory environmental cues overshadowed taste cues and gained greater associative control over the thermal response to ethanol injection. Another problem created by allowing subjects to control flavor intake is that the paired and unpaired groups differed in their exposure to the flavor CS on the tolerance test. Thus, group differences in associative strength controlled by taste stimuli may have been obscured by nonassociative factors related to the difference in fluid consumption. This problem was compounded by the fact that the fluid consumed by the unpaired group contained $10 \%$ ethanol. Differences in preinjection fluid consumption may also have confounded the within-group comparison of the paired groups' reactions to ethanol after access to the flavor CS versus their reactions to ethanol after access to water. Interpretation of that within-group comparison is further complicated by a difference in the time elapsed after the previous exposure to ethanol. The flavor $\mathrm{CS}$ test occurred $48 \mathrm{~h}$ after the previous ethanol injection, whereas the water test occurred only $24 \mathrm{~h}$ after the previous injection. Thus, the thermal response to ethanol in the water test may have been influenced by a "rebound hyperthermia" (Gallaher \& Egner, 1987; Sinclair \& Taira, 1988), whereas the response in the flavor test was not.

The present experiment was designed to provide an alternative test of the hypothesis that taste cues can participate in the associative control of tolerance to ethanol hypothermia. Rats were exposed to a differential Pavlovian conditioning procedure in which exposure to one flavor was regularly followed by injection of ethanol, whereas exposure to another flavor was followed by injection of saline. In order to maintain a constant CS-US relationship over trials, the experimenter controlled presentation of the CSs by manually infusing a fixed amount of flavor solution into the rat's mouth on each conditioning and test trial. Finally, to minimize the possible influence of rebound hyperthermia, all tolerance test trials occurred $48 \mathrm{~h}$ after the preceding ethanol injection.

\section{METHOD}

\section{Subjects}

The subjects were 31 naive adult male Holtzman albino rats with an initial mean weight of $385 \mathrm{~g}(S D=17)$. They were individually housed in stainless steel wire-mesh hanging cages in a colony room maintained on a normal 12-h light-dark cycle at an ambient temperature of $22^{\circ} \pm 1^{\circ} \mathrm{C}$. Experimental procedures were conducted during the light cycle. Food was available ad lib in the home cage throughout the experiment. Water was also continuously available in the home cage, except during the final test for flavor consumption (see Procedure).

Four days before the first habituation session, a telemetry device for detecting body temperature (Model M, MiniMitter Co., Sunriver,
OR) was surgically implanted in the peritoneal cavity of each rat while it was fully anesthetized with halothane gas. Radio telemetry was used to eliminate thermal changes that might be due to stress or drug-stress interactions (cf. Cunningham \& Bischof, 1987; Peris \& Cunningham, 1986, 1987). A more detailed description of the hardware and software used for biotelemetry can be found elsewhere (Cunningham \& Peris, 1983).

\section{Apparatus}

The animals were tested in chambers $(24 \times 20 \times 14 \mathrm{~cm})$ with acrylic side walls and lid, aluminum end panels, and a grid floor composed of 4-mm stainless steel rods mounted $1.5 \mathrm{~cm}$ apart. Each chamber was contained inside a ventilated, sound- and lightattenuating enclosure $(52 \times 52 \times 48 \mathrm{~cm})$. Ambient temperature in these enclosures was $22^{\circ}-25^{\circ} \mathrm{C}$.

\section{Procedure}

The experiment consisted of four phases: habituation, conditioning, tolerance tests, and flavor consumption tests. In each phase, experimental sessions were $90 \mathrm{~min}$ in duration and were conducted on a daily basis.

Habituation. The habituation phase lasted 3 days. On each day, all rats were transported from the colony to the laboratory and placed into the experimental chambers for $90 \mathrm{~min}$. No other treatment was given on Day 1. On Days 2 and 3, each rat received an oral infusion of tap water $(1 \mathrm{ml}) 10 \mathrm{~min}$ after arrival in the laboratory. The experimenter held the rat in one hand, placed the tip of a disposable plastic syringe into the rat's mouth, and infused water over the rat's tongue. The procedure took approximately $5 \mathrm{sec}$. Oral infusion was followed immediately by intraperitoneal injection of saline and placement into the experimental chamber. The purpose of this phase was to habituate animals to the apparatus and the infusion and injection procedures. In these and all subsequent sessions, body temperatures were recorded during successive 5-min intervals throughout the session.

Conditioning. Three groups were formed, matched for average body temperature during habituation: Group $S(n=11)$, Group $N$ $(n=10)$, and Group $C(n=10)$. During the conditioning phase (32 consecutive sessions), subjects received a $1-\mathrm{ml}$ oral infusion of flavor solution, followed immediately by an intraperitoneal injection and placement into the experimental chamber. Rats in Groups $\mathrm{S}$ and $\mathrm{N}$ received an ethanol $(+)$ injection $(2.25 \mathrm{~g} / \mathrm{kg} ; 19 \% \mathrm{v} / \mathrm{v}$ in saline) on odd-numbered days and a saline (-) injection $(15 \mathrm{ml} / \mathrm{kg})$ on even-numbered days. Injection solutions were administered at room temperature. Group C served as a no-drug control, receiving saline injections on all days. Group $S$ was infused orally with sucrose solution $(0.1 \mathrm{M})$ before each ethanol injection and with sodium chloride solution $(0.2 \mathrm{M})$ before each saline injection. The flavor-drug relationships were reversed for Group N. Rats in Group $\mathrm{C}$ received an equal number of infusions of each flavor solution. Thus, all groups were equated for exposure to the apparatus, handling/injection stress, and the two flavor solutions. However, only Groups $\mathrm{S}$ and $\mathrm{N}$ were expected to develop tolerance to ethanol-induced hypothermia. Moreover, if flavor is an effective cue for conditioned tolerance, expression of tolerance should depend on the presence of the ethanol-paired flavor.

Tolerance tests. After the final conditioning trial, all subjects were exposed to three tolerance tests. Each test was conducted like a CS + conditioning trial; the rats were given an oral flavor infusion followed by an injection of ethanol. The ethanol dose was $2.25 \mathrm{~g} / \mathrm{kg}$ on the first test and $3.0 \mathrm{~g} / \mathrm{kg}$ on the second and third tests. In each test, half of the rats in the two ethanol groups ( $\mathrm{S}$ and $\mathrm{N}$ ) received the flavor that had previously signaled ethanol injection, whereas the remaining rats received the flavor that had signaled saline injection. Specifically, on the first and third tests, half of the rats in each group were exposed to the flavor solution that had 
been given on $\mathrm{CS}+$ conditioning trials, whereas the other half received the flavor that had been given on $\mathrm{CS}$ - conditioning trials. The opposite flavor solution was given on the second test.

To maintain the flavor-drug association during the test phase, two pairs of conditioning trials ( $\mathrm{CS}+$ and $\mathrm{CS}-$ ) were given between the first and second tests; one pair of trials separated the second and third tests. An additional $\mathbf{C S}$ - conditioning trial was given during the session immediately following each tolerance test.

This phase concluded with a placebo test in which all subjects received an oral flavor infusion followed by an injection of saline. The flavor assignments were those used in the second tolerance test.

Flavor consumption tests. After the placebo test, water bottles were removed from the home cages and the animals were placed on a fluid-deprivation schedule. In the experimental chamber, on each of 2 consecutive days, all rats were given $90 \mathrm{~min}$ of free access to a drinking tube filled with tap water. On each of the next 2 days, the subjects received 90 -min access to a drinking tube containing one of the two flavor solutions. Half of the rats in each group had access to the CS + flavor on Day 1 and the CS - flavor on Day 2; order of presentation was reversed for the remaining rats. On both flavor test days, all subjects were given 5-min access to tap water in the home cage immediately after the test session. No oral infusions or injections were given during this phase of the experiment.

\section{RESULTS}

One rat in Group $\mathrm{S}$ was removed from the experiment during the conditioning phase because of poor health. Thus, the final number of subjects in each group was 10 .
Because of occasional difficulty in obtaining reliable telemetry signals, the temperature data for some subjects were discarded from one to three sessions. The actual numbers of subjects included in statistical analyses are indicated in the results.

\section{Habituation}

Body temperatures were elevated at the beginning of each session and increased slightly over the first $15 \mathrm{~min}$. For example, average temperature during the third 5-min sample period on Day 3 was $38.5^{\circ} \mathrm{C}$. This elevation in temperature is probably best attributed to the stress involved in being handled, transported, and injected (cf. Cunningham \& Bischof, 1987; Cunningham \& Peris, 1983). Thereafter, body temperatures declined steadily, reaching asymptote approximately $70-75 \mathrm{~min}$ after the session began. Habituation was evidenced as a small decrease over days in asymptotic temperature. Average temperature during the final $10 \mathrm{~min}$ of the session was $37.3^{\circ}, 37.2^{\circ}$, and $37.0^{\circ} \mathrm{C}$ on Days 1,2 , and 3 , respectively $(n=30)$.

\section{Conditioning}

The upper panels of Figure 1 show mean body temperature during successive 5-min sample periods on the first (left) and last (right) positive conditioning trials (i.e., odd-
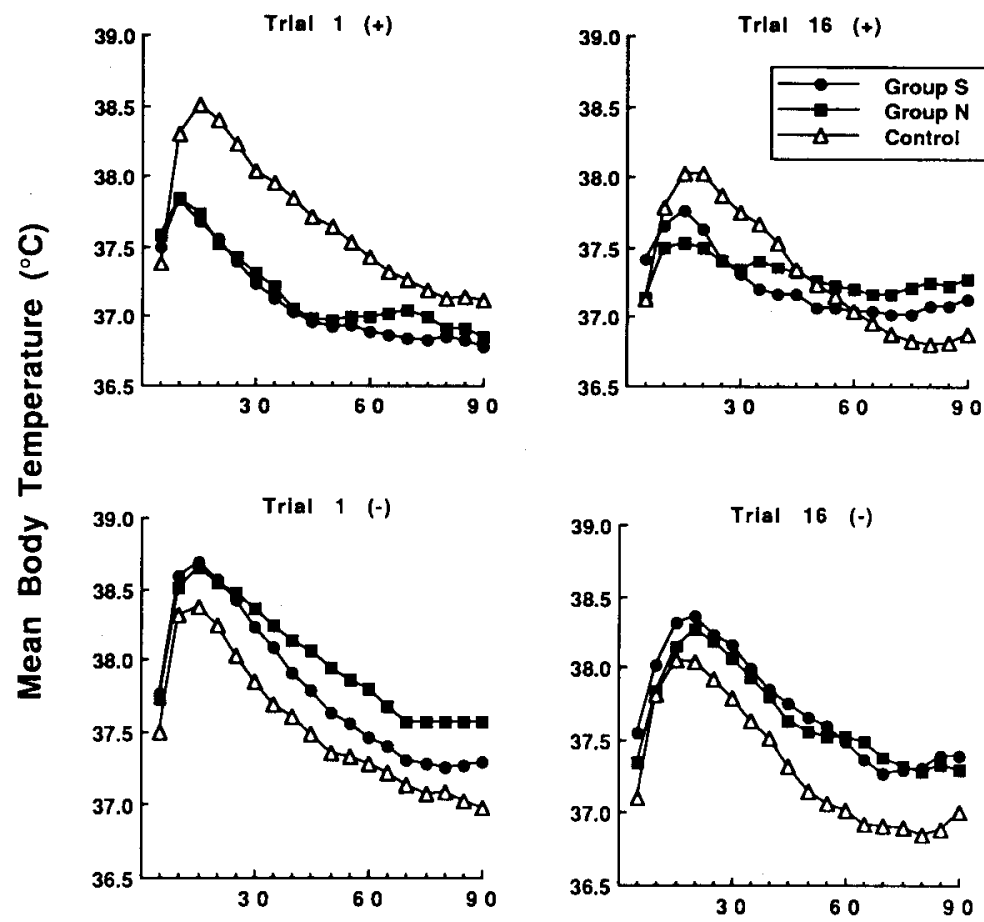

Minutes After Injection

Figure 1. Mean body temperature during successive 5-min sample periods on the first and last CS + and CS - conditioning trials for each group. Groups $S$ and $\mathrm{N}$ were injected with ethanol $(2.25 \mathrm{~g} / \mathrm{kg})$ on $\mathrm{CS}+$ trials and with saline on CStrials. Control animals always received saline. Data for controls are collapsed over flavor subgroup. 
numbered days; $n=10$ /group). Data for Group C are collapsed over the flavor subgroups. Group C's thermal response on Trial 1 was similar to that observed during the habituation phase, that is, an initial elevation in temperature followed by a steady decline. The ethanol-treated groups ( $\mathrm{S}$ and $\mathrm{N}$ ) showed lower temperatures. Ethanol attenuated the initial elevation in temperature and produced a mild hypothermia. By Trial 16, differences between Group $\mathrm{C}$ and the ethanol groups had diminished. It should be noted that temperatures recorded during the first one or two sample periods were artificially low because of the use of room-temperature $\left(20^{\circ}-22^{\circ} \mathrm{C}\right)$ injection solutions.

Separate two-way (groups $\times$ samples) analyses of variance were applied to the data shown in the upper panels of Figure 1. The alpha level for these and all subsequent analyses was set at .05. Analysis of Trial 1 yielded significant effects of groups $[F(2,27)=8.5]$, samples $[F(17,459)$ $=82.7]$, and groups $\times$ samples $[F(34,459)=6.0]$. On Trial 16, only the samples effect $[F(17,459)=20.2]$ and groups $\times$ samples interaction $[F(34,459)=3.7]$ were significant. Follow-up comparisons between Groups $S$ and $\mathrm{N}$ on each trial produced no effects involving the groups factor, indicating that flavor of the infused solution did not affect the thermal response to ethanol.

The lower panels of Figure 1 show mean body temperature during successive 5-min sample periods on the first (left) and last (right) negative conditioning trials (i.e., even-numbered days; $n=10 /$ group). As expected, Group C's thermal responses on these trials were nearly identical to its responses on odd-numbered days (upper panels). In contrast, experimental rats showed higher temperatures than did controls. Although there was an overall decline in temperature between the first and last trials, the difference between the ethanol groups and the control group remained the same. Separate analyses of each trial yielded reliable main effects of groups $[F \mathrm{~s}(2,27)=$ 12.8 and 5.9$]$ and samples $[F \mathrm{~s}(17,459)=94.9$ and 72.4$]$, but no interaction (both $F \mathrm{~s}<1.2$ ). Follow-up comparisons between Groups $\mathrm{S}$ and $\mathrm{N}$ on each trial produced no effects involving the groups factor, indicating that flavor of the orally infused solution did not affect the thermal response to saline injection.

\section{Tolerance Tests}

On the first tolerance test, Group $\mathrm{S}$ and $\mathrm{N}$ rats receiving ethanol after the positive flavor showed an average temperature of $37.2^{\circ} \mathrm{C}(n=9)$. Rats receiving ethanol after the negative flavor $(n=10)$ showed the same average temperature, suggesting that flavor had not become an effective cue for conditioned tolerance. However, the temperatures shown by these animals were only slightly higher than those of control rats receiving ethanol for the first time $\left(37.0^{\circ} \mathrm{C}, n=10\right)$. A groups $\times$ samples analysis failed to yield any significant effects involving the groups factor.

To rule out the possibility that body temperatures were in a range that was insensitive to the signaling effects of flavor, the ethanol dose was increased from 2.25 to
$3.0 \mathrm{~g} / \mathrm{kg}$ for the second and third tolerance tests. The outcome of these tests is shown in Figure 2. The two upper curves depict the experimental rats' temperature response to ethanol given after infusion of the positive and negative flavor solutions (collapsed over flavor treatment group; Group $\mathrm{S}, n=9$; Group $\mathrm{N}, n=7$ ). The lower curve depicts the ethanol response in control animals (collapsed over flavor; $n=9$ ). Relative to the first test, overall temperatures decreased and the difference between experimental and control animals increased, providing evidence of thermal tolerance. As in the first tolerance test, however, the flavor stimuli produced no effect on the thermal response of experimental animals, indicating that flavor had not become a cue for conditioned tolerance.

A three-way (groups $\times$ flavor $\times$ samples) analysis of the data from the second and third tolerance tests yielded significant effects of groups $[F(2,22)=4.6]$, samples $[F(17,374)=34.2]$, and groups $\times$ samples $[F(34,374)=$ 1.6]. Follow-up comparisons indicated that Groups $S$ and $\mathrm{N}$ did not differ from each other, but that together they were less hypothermic than controls $[F(1,22)=6.6]$.

The placebo test indicated that the response of experimental animals to saline injection was also unaffected by the flavor stimuli. Group $\mathbf{S}$ and $\mathbf{N}$ rats receiving saline showed an average temperature of $37.7^{\circ} \mathrm{C}$ after the positive flavor $(n=7)$ and $37.5^{\circ} \mathrm{C}$ after the negative flavor $(n=10)$. Control rats showed an average temperature of $37.6^{\circ} \mathrm{C}(n=8)$. A groups $\times$ samples analysis did not yield any reliable effects involving the groups factor. The lack of difference between experimental and control animals on this test may be due to the fact that controls had recently received three exposures to ethanol (i.e., "positive conditioning trials") during tolerance testing.

\section{Flavor Consumption Tests}

Figure 3 shows the mean amount of each flavor consumed by each group in the final drinking tests. In each of the ethanol-treated groups ( $\mathrm{S}$ and $\mathrm{N}$ ), subjects drank

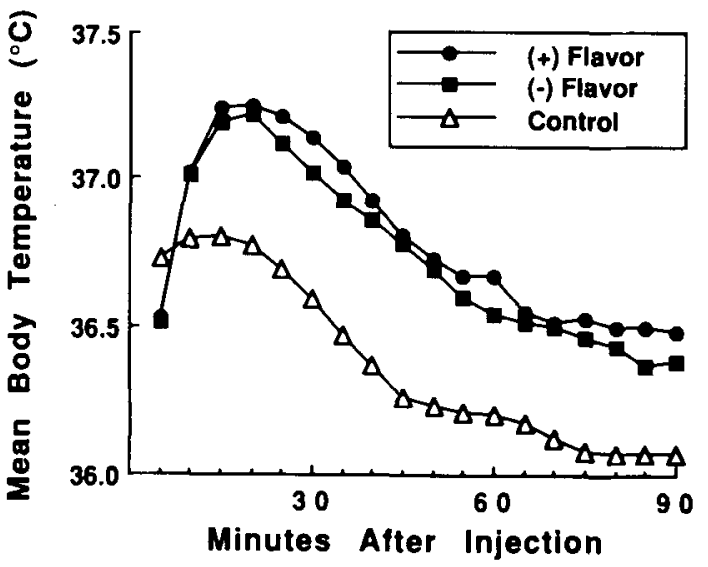

Figure 2. Mean body temperature during successive 5-min sample periods on the second and third tolerance tests. Animals were injected with ethanol $(3 \mathrm{~g} / \mathrm{kg})$ after infusion of the flavor that had previously served as CS + (+ flavor) or CS - ( - flavor). Control animals also received ethanol after both flavors (data collapsed). 


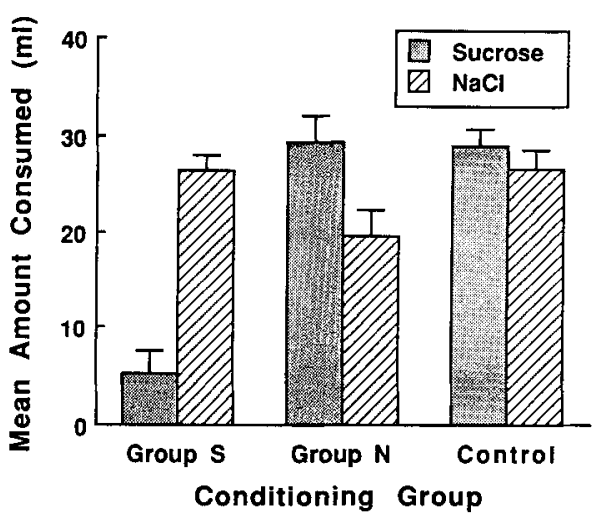

Figure 3. Mean amounts $( \pm S E M)$ of sucrose and sodium chloride ( $\mathrm{NaCl}$ ) consumed by each group during the final 90-min drinking tests.

less of the ethanol-paired flavor than of the saline-paired flavor, indicating that the conditioning procedure had established an aversion for the positive flavor. Control animals showed no aversion, drinking approximately equal amounts of each flavor solution. A groups $\times$ flavor analysis produced significant effects of groups $[F(2,27)=$ 12.5], flavor $[F(1,27)=34.1]$, and groups $\times$ flavor $[F(2,27)=17.5]$. Follow-up analyses of the flavor effect within each group were reliable for Groups $S[F(1,9)=$ $84.2]$ and $\mathrm{N}[F(1,9)=6.4]$, but not for the control group $[F(1,9)=1.6]$.

\section{DISCUSSION}

In this study, repeated injection of ethanol after exposure to a distinctive flavor stimulus resulted in development of flavor aversion and tolerance to ethanol-induced hypothermia. However, despite clear evidence of a flavorethanol association, flavor had no effect on the expression of tolerance. This outcome is consistent with the findings of Sinclair (1984), but its interpretation is not complicated by variations in the CS-US relationship during conditioning or by differences in CS exposure or time elapsed after previous ethanol exposure during testing.

The development of aversion to the ethanol-paired flavor indicates that the failure to show conditioned stimulus control of ethanol's thermal effect by these taste cues cannot be attributed to lack of salience. Rather, one must conclude either that tolerance was controlled by nongustatory conditioned stimuli (e.g., visual, tactile, auditory features of the recording apparatus) or that all of the tolerance was due to nonassociative factors (cf. Goudie \& Demellweek, 1986). Given the similarity between the procedure used here and those used in previous demonstrations of associative control over tolerance by exteroceptive cues (e.g., Mansfield \& Cunningham, 1980), it seems reasonable to propose that the distinctive environmental cues provided by the testing chamber were capable of acquiring associative control over ethanol's thermal effect. Although they were less predictive of ethanol than the paired flavor stimulus, distinctive environmental cues were paired with ethanol on a $50 \%$ reinforcement schedule. Partial reinforcement has been shown to retard, but does not prevent acquisition of conditioned tolerance (Krank, Hinson, \& Siegel, 1984; Siegel, 1977).

To explain why the more predictive taste cues did not acquire greater control over ethanol's thermal response than did environmental cues, one could appeal to the notion of selective association (Garcia \& Koelling, 1966; LoLordo, 1979). Specifically, one might propose that taste cues more readily gain control over ethanol's effect on ingestive behavior, whereas environmental cues more readily gain control over ethanol's thermal effect. Selective association has recently been invoked in a similar way to explain the differential effects of taste and environmental cues on the conditioning of immune system responses (Krank \& MacQueen, 1988). Although the present findings can be explained by this mechanism, additional groups would be needed to provide unequivocal evidence of selective association (cf. LoLordo, 1979).

One aspect of the present findings that may bear on the foregoing interpretation is the hyperthermia observed in Groups $\mathrm{S}$ and $\mathrm{N}$ after saline injection on $\mathrm{CS}-$ conditioning trials (see lower panels of Figure 1). This hyperthermia may represent a conditioned compensatory re sponse evoked by partially reinforced environmental cues (Crowell et al., 1981; Le et al., 1979; Mansfield \& Cunningham, 1980). On the other hand, because CS - trials were always given $24 \mathrm{~h}$ after an ethanol injection for Groups $S$ and $N$, the elevation in body temperature could simply represent an unconditioned compensatory ("rebound") hyperthermia (Gallaher \& Egner, 1987; Sinclair \& Taira, 1988). Another possibility is that alternate-day injection of ethanol retarded habituation of the hyperthermic response to being transported, handled, and injected (cf. Izquierdo, 1979). However, one feature of the data that is troublesome for all of these explanations is that the magnitude of the difference between experimental and control groups on CS - trials remained constant over trials. One would ordinarily expect a group difference due to conditioning to increase in magnitude over trials, especially if conditioning was supposed to be mediating the gradual development of tolerance to ethanol hypothermia. Conversely, one might expect the group difference to decrease over trials either because tolerance reduced rebound hyperthermia (Sinclair \& Taira, 1988) or because repeated exposure to handling and injection without ethanol (on CS - trials) produced habituation. In the absence of additional information (e.g., whether or not hyperthermia was specific to the test environment), it is difficult to favor one explanation over the others. Further research is needed to clarify the mechanism(s) underlying the hyperthermia observed on CS - trials.

The finding that taste cues do not acquire associative control over tolerance to ethanol hypothermia is especially interesting in light of recent findings suggesting that ethanol's thermal effect may be partially involved in regulating self-administration of ethanol and in determining the strength of ethanol-induced conditioned taste aver- 
sion (Cunningham, Hawks, \& Niehus, 1988; Cunningham $\&$ Niehus, 1989). When considered together with those findings, the present results suggest that taste cues acquire associative control over ingestive behavior based, in part, on changes in a physiological system that is not itself directly affected by a taste-drug association. However, that physiological system is affected by an association between environmental cues and drug. One implication of these considerations is that an environment-drug association that reduces ethanol hypothermia by establishing a conditioned thermal response should retard development of conditioned taste aversion. Thus, it may be that the well-documented attenuation of taste-aversion conditioning by ethanol preexposure (e.g., Barker \& Johns, 1978; Berman \& Cannon, 1974; Cannon, Baker, \& Berman, 1977 ) is due to conditional control of hypothermic tolerance by drug-associated environmental cues. Although the account proposed here is similar in many respects to the associative theory of the US preexposure phenomenon based on blocking (cf. Randich \& LoLordo, 1979), it attributes retardation of conditioned taste aversion to the associatively mediated reduction in ethanol hypothermia rather than to competition between taste and contextual cues for association with ethanol.

\section{REFERENCES}

Baker, T. B., Morse, E., \& Sherman, J. E. (1986). The motivation to use drugs: A psychobiological analysis of urges. In P. C. Rivers (Ed.), Nebraska Symposium on Motivation (Vol. 34, pp. 257-323). Lincoln: University of Nebraska Press.

BARKER, L. M., \& JoHNS, T. (1978). Effect of ethanol preexposure on ethanol-induced conditioned taste aversion. Journal of Studies on Alcohol, 39, 39-46.

Berman, R. F., \& Cannon, D. S. (1974). The effect of prior ethanol experience on ethanol-induced saccharin aversions. Physiology \& Behavior, 12, 1041-1044.

Cannon, D. S., Baker, T. B., \& Berman, R. F. (1977). Taste aversion disruption by drug pretreatment: Dissociative and drug-specific effects. Pharmacology, Biochemistry \& Behavior, 6, 93-100.

Crowell, C. R., Hinson, R. E., \& Siegel, S. (1981). The role of conditional drug responses in tolerance to the hypothermic effects of ethanol. Psychopharmacology, 73, 51-54.

Cunningham, C. L., \& Bischof, L. L. (1987). Stress and ethanolinduced hypothermia. Physiology \& Behavior, 40, 377-382.

Cuniningham, C. L., Crabbe. J. C., \& Rigter, H. (1984). Pavlovian conditioning of drug-induced changes in body temperature. Pharmacology \& Therapeutics, 23, 365-391.

Cunningham, C. L., Hawks, D. M., \& Niehus, D. R. (1980). Role of hypothermia in ethanol-induced conditioned taste aversion. Psychopharmacology, 95, 318-322.

Cunningham, C. L., \& Niehus, D. R. (1989). Effect of ingestioncontingent hypothermia on ethanol self-administration. Alcohol, 6, 377-380.

Cunningham, C. L., \& Peris, J. (1983). A microcomputer system for temperature biotelemetry. Behavior Research Methods \& Instrumentation, 15, 598-603.

Gallaher, E. J., \& EgNer, D. A. (1987). Rebound hyperthermia follows ethanol-induced hypothermia in rats. Psychopharmacology, 91, 34-39.

Garcia, J., \& Koelling, R. A. (1966). Relation of cue to consequence in avoidance learning. Psychonomic Science, 4, 123-124.

Goudie, A. J., \& Demellweek, C. (1986). Conditioning factors in drug tolerance. In S. R. Goldberg \& I. P. Stolerman (Eds.), Be- havioral analysis of drug dependence (pp. 225-285). New York: Academic Press.

Greeley, J., Le, A. D., Poulos, C. X., \&appell, H. (1984). Alcohol is an effective cue in the conditional control of tolerance to alcohol. Psychopharmacology, 83, 159-162.

Hinson, R. E., \& Siegel, S. (1980). The contribution of Pavlovian conditioning to ethanol tolerance and dependence. In $\mathrm{H}$. Rigter \& J. C. Crabbe, Jr. (Eds.), Ethanol tolerance and dependence (pp. 181199). Amsterdam: Elsevier/North-Holland Biomedical Press.

Hodgson, R. J., \& RANKIN, H. J. (1976). Modification of excessive drinking by cue exposure. Behavior Research \& Therapy, 14, 305-307.

IZQUIERDO, I. (1979). Effect of naloxone and morphine on various forms of memory in the rat: Possible role of endogenous opiate mechanisms in memory consolidation. Psychopharmacology, 66, 199-203.

Krank, M. D., Hinson, R. E., \& Siegel, S. (1984). Effect of partial reinforcement on tolerance to morphine-induced analgesia and weight loss in the rat. Behavioral Neuroscience, 98, 72-78.

Krank, M. D., \& MacQueen, G. M. (1988). Conditioned compensatory responses elicited by environmental signals for cyclophosphamideinduced suppression of antibody production in mice. Psychobiology, 16, 229-235.

LE, A. D., Poulos, C. X., \& Cappell, H. (1979). Conditioned tolerance to the hypothermic effect of ethyl alcohol. Science, 206, 1109-1110.

LoLoRDo, V. M. (1979). Selective associations. In A. Dickinson \& R. A. Boakes (Eds.), Mechanisms of leaming and motivation (pp. 367398). Hillsdale, NJ: Erlbaum.

Mansfield, J. G., \& Cunningham, C. L. (1980). Conditioning and extinction of tolerance to the hypothermic effect of ethanol in rats. Journal of Comparative \& Physiological Psychology, 94, 962-969.

Melchior, C. L., \& TabakofF, B. (1981). Modification of environmentally cued tolerance to ethanol in mice. Journal of Pharmacology \& Experimental Therapeutics, 219, 175-180.

Peris, J., \& Cunningham, C. L. (1986). Handling-induced enhancement of alcohol's acute physiological effects. Life Sciences, 38 , 273-279.

Peris, J., \& Cunningham, C. L. (1987). Stress enhances the development of tolerance to the hypothermic effect of ethanol. Alcohol \& Drug Research, 7, 187-193.

RANDICH, A., LOLORDO, V. M. (1979). Associative and nonassociative theories of the UCS preexposure phenomenon: Implications for Pavlovian conditioning. Psychological Bulletin, 86, 523-548.

Sherman, J. E., Jorenby, D. E., \& Baker, T. B. (1988). Classical conditioning with alcohol: Acquired preferences and aversions, tolerance, and urges/craving. In C. D. Chaudron \& D. A. Wilkinson (Eds.), Theories on alcoholism (pp. 173-237). Toronto: Addiction Research Foundation.

SIEGEL, S. (1977). Morphine tolerance acquisition as an associative process. Joumal of Experimental Psychology: Animal Behavior Processes, 3, 1-13.

SIEGEL, S. (1985). Drug-anticipatory responses in animals. In L. White, B. Tursky, \& G. E. Schwartz (Eds.), Placebo: Theory, research, and mechanisms (pp. 288-305). New York: Guilford.

SIEGEL, S. (1989). Pharmacological conditioning and drug effects. In A. I. Goudie \& M. W. Emmett-Oglesby (Eds.), Psychoactive drugs: Tolerance and sensitization (pp. 115-180). Clifton, NJ: Humana.

Siegel, S., KRank, M. D., \& Hinson, R. E. (1987). Anticipation of pharmacological and nonphàminacological events: Classical conditioning and addictive behavior. Journal of D̄riğ Issues, 17, 83-110.

SinCLAIR, J. D. (1984). Ethanol-induced conditioned taste aversion to ethanol. Alcohol, 1, 223-227.

Sinclair, J. D., \& TAIRA, T. (1988). Hangover hyperthermia in rats: Relation to tolerance and external stimuli. Psychopharmacology, 94, 161-166.

Stewart, J., \& Eikelboom, R. (1987). Conditioned drug effects. In L. L. Iversen, S. D. Iversen, \& S. H. Snyder (Eds.), New directions in behavioral pharmacology (pp. 1-57). New York: Plenum.

(Manuscript received January 15, 1990; revision accepted for publication October 24,1990 .) 